Article

\title{
Thermal Behaviour of Microgels Composed of Interpenetrating Polymer Networks of Poly( $N$-isopropylacrylamide) and Poly(acrylic acid): A Calorimetric Study
}

\author{
Silvia Franco ${ }^{1,2}\left(\mathbb{D}\right.$, Elena Buratti ${ }^{2}\left(\mathbb{D}\right.$, Valentina Nigro ${ }^{2,3}\left(\mathbb{D}\right.$, Monica Bertoldo ${ }^{4,5}\left(\mathbb{D}\right.$, Barbara Ruzicka ${ }^{2,6, *(\mathbb{D})}$ \\ and Roberta Angelini $2,6, *$ (D)
}

1 Department of Basic and Applied Sciences for Engineering, Sapienza University of Rome, Via Antonio Scarpa 14, 00161 Roma, Italy; silvia.franco@uniroma1.it

2 Institute of Complex Systems (ISC-CNR), Sede Sapienza, Piazzale Aldo Moro 2, 00185 Roma, Italy; elena.buratti@roma1.infn.it (E.B.); valentina.nigro@enea.it (V.N.)

3 Photonics Micro and Nanostructures Laboratory, Fusion and Technologies for Nuclear Safety and Security Department, ENEA C.R. Frascati, V. E. Fermi, 45, 00044 Frascati, Italy

4 Department of Chemical and Pharmaceutical Sciences, University of Ferrara, 44121 Ferrara, Italy; brtmnc@unife.it

5 Institute of Organic Synthesis and Photoreactivity (ISOF-CNR), Via Piero Gobetti, 101, 49128 Bologna, Italy

6 Department of Physics, Sapienza University of Rome, Piazzale Aldo Moro 2, 00185 Roma, Italy

* Correspondence: barbara.ruzicka@cnr.it (B.R.); roberta.angelini@cnr.it (R.A.)

\section{check for}

updates

Citation: Franco, S.; Buratti, E.;

Nigro, V.; Bertoldo, M.; Ruzicka, B.; Angelini, R. Thermal Behaviour of Microgels Composed of Interpenetrating Polymer Networks of Poly( $\mathrm{N}$-isopropylacrylamide) and Poly(acrylic acid): A Calorimetric Study. Polymers 2022, 14, 115. https://doi.org/10.3390/ polym 14010115

Academic Editor: Thomas Hellweg

Received: 16 December 2021

Accepted: 26 December 2021

Published: 29 December 2021

Publisher's Note: MDPI stays neutral with regard to jurisdictional claims in published maps and institutional affiliations.

Copyright: (C) 2021 by the authors. Licensee MDPI, Basel, Switzerland. This article is an open access article distributed under the terms and conditions of the Creative Commons Attribution (CC BY) license (https:// creativecommons.org/licenses/by/ $4.0 /)$.

\begin{abstract}
Stimuli-responsive microgels have recently attracted great attention in fundamental research as their soft particles can be deformed and compressed at high packing fractions resulting in singular phase behaviours. Moreover, they are also well suited for a wide variety of applications such as drug delivery, tissue engineering, organ-on-chip devices, microlenses fabrication and cultural heritage. Here, thermoresponsive and $\mathrm{pH}$-sensitive cross-linked microgels, composed of interpenetrating polymer networks of poly( $N$-isopropylacrylamide) (PNIPAM) and poly(acrylic acid) (PAAc), are synthesized by a precipitation polymerization method in water and investigated through differential scanning calorimetry in a temperature range across the volume phase transition temperature of PNIPAM microgels. The phase behaviour is studied as a function of heating/cooling rate, concentration, $\mathrm{pH}$ and PAAc content. At low concentrations and PAAc contents, the network interpenetration does not affect the transition temperature typical of PNIPAM microgel in agreement with previous studies; on the contrary, we show that it induces a marked decrease at higher concentrations. DSC analysis also reveals an increase of the overall calorimetric enthalpy with increasing concentration and a decrease with increasing PAAc content. These findings are discussed and explained as related to emerging aggregation processes that can be finely controlled by properly changing concentration, PAAc content an $\mathrm{pH}$. A deep analysis of the thermodynamic parameters allows to draw a temperature-concentration state diagram in the investigated concentration range.
\end{abstract}

Keywords: calorimetry; thermoresponsiveness; microgels; soft colloids; rheology; glass; jamming; poly( $N$-isopropylacrylamide)

\section{Introduction}

The interest in colloidal systems extends from fundamental studies [1] to technological applications [2,3]. Due to their relatively large dimensions with respect to atomic and molecular systems $[4,5]$, they are characterized by lengths and time scales easily accessible with a wide variety of laboratory techniques. Moreover, their effective interactions can be properly tuned either by synthesis and by chemical-physical parameters [6] giving rise to complex phase diagrams [7-12]. Among colloidal systems, microgels, particles of almost spherical shape made of crosslinked polymer networks, dispersed in a solvent, are very intriguing systems [1,13]. Particles of size between nanometers and microns, and 
the possibility of finely tuning their properties by changing the chemical composition during synthesis, open the door to many perspectives. Besides morphological aspects, one of the main advantages of some microgel particles is their ability to respond to environmental stimuli [1]. In particular, depending on the nature of the constituent monomers, microgel particles could manifest high sensitivity to changes of temperature, $\mathrm{pH}$, electric field, ionic strength, solvent and light pulses [14-16]. Interestingly, they offer manifold possibilities in several research fields thanks to their polymer/colloid duality [17]. Indeed, the responsiveness of microgels, coupled with their versatility and relatively easy synthesis methods [18], makes them attractive for several applications, such as drug delivery [19-25], tissue engineering in artificial muscle [21], bone [26] and cartilage fabrications [27-29], for organ-on-chip [30] and microlenses [31,32] device development. Moreover, films based on thermo- and $\mathrm{pH}$-sensitive microgels have been developed to obtain three-dimensional macromaterials [33-35] and they have been also used to create photonic crystals like structures [36]. Of note, microgels also find applications in cultural heritage conservation for cleaning of modern and ancient paper [37]. Among all the available stimuli-responsive polymer-based microgels, temperature-sensitive ones are the most popular since, by tuning temperature, they can be easily controlled by changing their size, hydrophilicity and softness, reaching high packing fractions $[38,39]$. Indeed, the most extensively investigated temperature sensitive microgels are those based on poly( $N$-isopropylacrylamide) (PNIPAM) that presents a Lower Critical Solution Temperature (LCST) in water at $305 \mathrm{~K}$. LCST signs the crossover between dominant hydrophilic and hydrophobic interactions between water molecules and PNIPAM polymer [40]. At temperatures below the LCST in fact, water is a good solvent for PNIPAM and polymer chains are hydrated and solvated by water due to strong hydrogen bonds between water and the amide groups (CONH) of PNIPAM. However, the hydrophilic/hydrophobic interactions between water molecules and PNIPAM chains are highly temperature sensitive and when temperature is increased, PNIPAM chains become increasingly hydrophobic [40] undergoing a transition at the LCST, from a coiled and enthalpic favoured structure into an entropically favoured and dense globular one [41,42]. The coil-to-globule transition of PNIPAM polymer characterizes the behaviour of PNIPAM-based microgels that swell at low temperatures, with large numbers of water molecules retained into the crosslinked polymeric structure, and deswell at higher temperatures when water is expelled from the particles giving rise to the typical Volume Phase Transition (VPT) [43,44].

Therefore, to investigate the basic mechanisms of thermoresponsive smart microgels, Differential Scanning Calorimetry (DSC) turns out to be one of the most suitable techniques [45], generally employed to study the thermal transitions of polymeric materials, food and pharmaceutical products, glasses and ceramics, biological macromolecules such as proteins, and in general of soft materials with significant transitions with temperature [46-52]. Several works have been conducted over the past 20 years, with the aim to investigate, through DSC, the thermal behaviour of hydrogels [53-55] and microgels [56-59]. For instance, the thermal behaviour of PNIPAM-PNIPMAM core shell microgels in $\mathrm{D}_{2} \mathrm{O}$ solution has been studied by varying the core-shell mass ratio in order to control the mutual influences of the two polymers [60]. Indeed, these particles showed a two-step shrinking behaviour, corresponding to the contributions of the core and the shell, respectively. In the same years, always through DSC, Hoare and Pelton studied the thermal phase transitions of a range of NIPAM-based carboxylic acid-functionalized microgels with well-defined radial and chain functional group distributions [57]. Thermograms displayed a two-peak transition, like in core-shell microgels, induced by the local heterogeneities within the functionalized microgel. In this way, the ratio between the two transition temperatures gives an idea of the radial functional group distribution. Furthermore, PNIPAM microgels with different crosslinker contents were investigated through DSC analysis [56] in order to evaluate the crosslinker contribution, revealing an increase of the transition temperature and a decrease of the overall calorimetric enthalpy with increasing crosslinker concentration. In a further study, the VPT and the fluid-to-glass 
transition of PNIPAM microgels have been studied through rheological and calorimetric measurements at various concentrations [58]. Always on PNIPAM microgel, the investigation of the volume phase transition has been carried out combining elastic incoherent neutron scattering and differential scanning calorimetry starting from polymer weight concentration of $30 \%$ up to dry conditions [59]. They outlined that the VPT emerges from the complex amphiphilic nature of the polymer that is composed by a hydrophobic backbone decorated with side chain groups containing both hydrophilic amide moieties and hydrophobic isopropyl ones. In a very recent work [61] the role of water-polymer interactions on the VPT, the melting and crystallization processes of PNIPAM linear chains and PNIPAM microgels have been deeply investigated. DSC measurements up to $80 \%$ of weight concentration were performed to investigate the role of polymer structure and to probe the capability of efficiently confining water. The aging of the samples and the properties of non-deuterated and deuterated microgels were also studied. Of note, colloidal PNIPAM microgels crosslinked with bisacrylamide and with acrylic acid as a comonomer, have been investigated as a function of temperature, $\mathrm{pH}$ and ionic strength and then compared with standard PNIPAM [62] displaying different properties. Since the copolymers are temperature-, $\mathrm{pH}$ - and electrolyte-sensitive, they offer significant advantages over their homopolymeric analogues having additional "triggering" variables. Moreover, the porous structures of a copolymer microgel of NIPAM and acrylic acid and a poly(acrylic acid) microgel were compared through the measurement of their thermal behaviours [63]. Very recently, microgels functionalized by the introduction of acrylic acid as comonomer or interpenetrating polymer network have been investigated by high-sensitivity differential scanning calorimetry in order to understand their thermoresponsive behaviour [64]. It was found that, in the case of interpenetrating networks, the transition temperature typical of PNIPAM was not notably affected and that the transition cooperativity was reduced at variance with the copolimer network that revealed a highly cooperative thermoresponsive behaviour. In recent years, the investigation of PNIPAM and PNIPAM/PAAc microgels has highly increased as is also demonstrated in the list in Table 1 that reports manuscripts which appeared in the Polymers journal in 2021 on similar topics.

Table 1. Table of the articles published in Polymers in 2021 about PNIPAM based microgels.

\begin{tabular}{|c|c|c|c|}
\hline Reference & $\begin{array}{l}\text { Investigated } \\
\text { System }\end{array}$ & $\begin{array}{l}\text { Highlighted } \\
\text { Topic }\end{array}$ & $\begin{array}{l}\text { Investigation } \\
\text { Techniques }\end{array}$ \\
\hline Sennato et al. [16] & $\begin{array}{l}\text { PNIPAM } \\
\text { microgels }\end{array}$ & $\begin{array}{l}\text { electrostatic } \\
\text { behaviour }\end{array}$ & $\begin{array}{l}\text { DLS, TEM, AFM, } \\
\text { electrophoresis, viscosimetry }\end{array}$ \\
\hline Annegarn et al. [18] & $\begin{array}{l}\text { P(NIPAM-co-APMH) } \\
\text { microgels }\end{array}$ & $\begin{array}{l}\text { electrostatic } \\
\text { behaviour }\end{array}$ & $\begin{array}{l}\text { DLS, AFM, } \\
\text { H-NMR }\end{array}$ \\
\hline Nasimova et al. [34] & $\begin{array}{c}\text { Macromaterials of } \\
\text { PNIPAM-PAAc } \\
\text { IPN microgels }\end{array}$ & $\begin{array}{l}\text { macromaterial } \\
\text { properties }\end{array}$ & $\begin{array}{c}\text { FTIR, } \\
\text { computer simulations }\end{array}$ \\
\hline Buratti et al. [35] & $\begin{array}{c}\text { Films of PNIPAM-PAAc } \\
\text { IPN microgels }\end{array}$ & $\begin{array}{c}\text { layer } \\
\text { characterization }\end{array}$ & $\begin{array}{c}\text { DLS, H-NMR, } \\
\text { AFM contact angle }\end{array}$ \\
\hline Nigro et al. [65] & $\begin{array}{l}\text { PNIPAM-PAAc } \\
\text { IPN microgels }\end{array}$ & $\begin{array}{l}\text { physical } \\
\text { behaviour }\end{array}$ & $\begin{array}{l}\text { DLS, SANS, Raman, } \\
\text { rheology, electrophoresis }\end{array}$ \\
\hline
\end{tabular}

At variance with previous studies, here we report an extensive calorimetric study on a microgel composed of Interpenetrating Polymer Networks (IPN) of PNIPAM and poly(acrylic acid) (PAAc), thermo- and $\mathrm{pH}$-sensitive respectively. As previously described, PNIPAM polymer undergoes a reversible coil-to-globule transition around the LCST (305 K), while PAAc undergoes a reversible coil-to-globule transition around a $\mathrm{pH}$ value close to the $\mathrm{pKa} \approx 4.5$ that depends on the ionization state of the carboxylic group $(\mathrm{COOH})$. As the $\mathrm{pH}$ is increased above the $\mathrm{pKa}$, ionization into $\mathrm{H}^{+}+\mathrm{RCOO}^{-}$is favoured and the polymer expands into a fully solvated open coil conformation (hydrophilic). However, at 
low $\mathrm{pH}$, carboxylic group are fully protonated (hydrophobic) and PAAc adopts a more compact globular conformation. The characteristics of the two constituent polymers give rise to an IPN microgel whose VPT can be controlled by properly tuning temperature, $\mathrm{pH}$ and the mutual content of PNIPAM and PAAc. This allows to finely control microgel properties through an ad-hoc synthesis procedure. Here we synthesize IPN microgel, by a precipitation polymerization method in water, and we investigate their behaviour through differential scanning calorimetry across the volume phase transition temperature of PNIPAM microgels as a function of heating/cooling rate, concentration, $\mathrm{pH}$ and PAAc content. Indeed, a deep analysis of the thermodynamic parameters allows us to draw a temperature-concentration state diagram in the investigated concentration range. To the best of our knowledge, a similar study has never been reported before.

\section{Materials and Methods}

\subsection{Materials}

$\mathrm{N}$-isopropylacrylamide (NIPAM) monomer, acrylic acid (AAc), sodium dodecyl sulphate (SDS) (98\% purity), potassium persulfate (KPS) (98\% purity), ammonium persulfate (APS) (98\% purity), $\mathrm{N}, \mathrm{N}, \mathrm{N}^{\prime}, \mathrm{N}^{\prime}$-tetramethylethylenediamine (TEMED) (99\% purity), ethylenediaminetetraacetic acid (EDTA), $\mathrm{NaHCO}_{3}$, all from Sigma-Aldrich (St. Louis, $\mathrm{MO}, \mathrm{USA}$ ), and the crosslinker $\mathrm{N}, \mathrm{N}^{\prime}$-methylene-bis-acrylamide (BIS), from Eastman Kodak (Rochester, NY, USA), were used. NIPAM monomer and BIS, used as crosslinker, were recrystallized from hexane and methanol respectively, dried under reduced pressure $(0.01 \mathrm{mmHg})$ at room temperature and stored at $253 \mathrm{~K}$. AAc monomer was purified by distillation $(40 \mathrm{mmHg}, 337 \mathrm{~K})$ under nitrogen atmosphere in presence of hydroquinone and stored at $253 \mathrm{~K}$. SDS, used as surfactant, KPS and APS, used as initiators, TEMED, a reaction accelerator, EDTA, a chelating agent for purifying dialysis membranes, and $\mathrm{NaHCO}_{3}$, were all used as received. All other solvents were RP grade (Carlo Erba, Cornaredo, Italy) and were used as received. Ultrapure water (resistivity: $18.2 \mathrm{M} \Omega / \mathrm{cm}$ at $298 \mathrm{~K}$ ) was obtained with Sarium ${ }^{\circledR}$ pro Ultrapure water purification Systems, Sartorius Stedim, Göttingen, Germany. A dialysis tubing cellulose membrane, MWCO 14,000 Da, (Sigma-Aldrich) was cleaned before use by washing with running distilled water for $3 \mathrm{~h}$, treated at $343 \mathrm{~K}$ for 10 min into a solution containing $3.0 \% \mathrm{NaHCO}_{3}$ and $0.4 \%$ EDTA weight concentration, rinsed in distilled water at $343 \mathrm{~K}$ for $10 \mathrm{~min}$ and then in fresh distilled water at room temperature for $2 \mathrm{~h}$.

\subsection{Microgel Synthesis}

IPN microgels were obtained by a sequential free radical polymerization method $[66,67]$ interpenetrating PAAc network in PNIPAM microgels, synthesized by a precipitation polymerization method following the procedure described by Pelton and et al. [13] as illustrated in Figure 1.

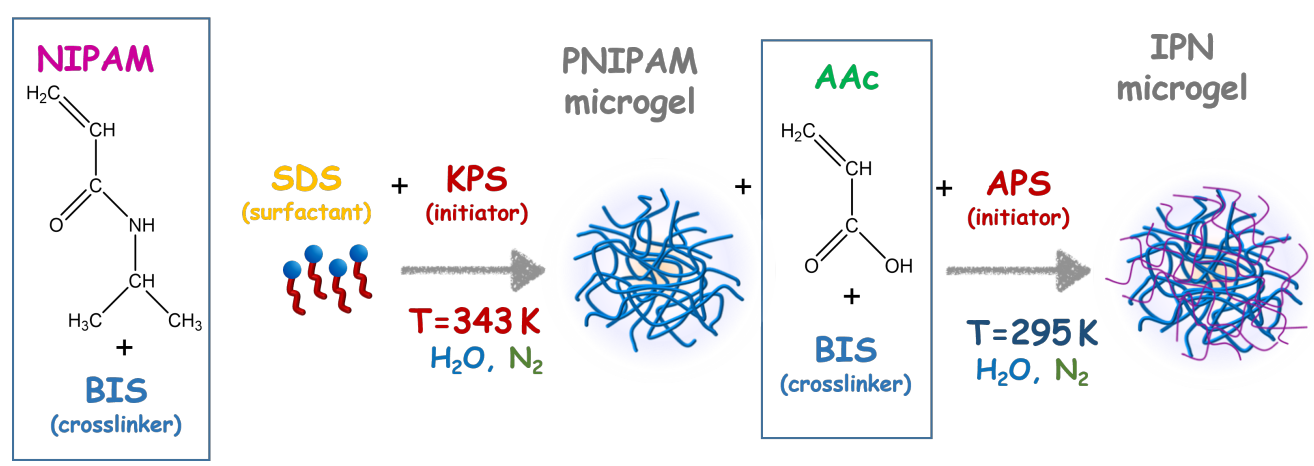

Figure 1. Schematic representation of the synthesis process that involves $N$-isopropylacrylamide (NIPAM) and acrylic acid (AAc) monomers, the crosslinker $\mathrm{N}, \mathrm{N}^{\prime}$-methylene-bis-acrylamide (BIS) and the reagents: sodium dodecyl sulphate (SDS), potassium persulfate (KPS), ammonium persulfate (APS). 
In the synthesis, $(24.162 \pm 0.001) \mathrm{g}$ of NIPAM monomer, $(0.4480 \pm 0.0001) \mathrm{g}$ of crosslinker BIS and $(3.5190 \pm 0.0001) \mathrm{g}$ of surfactant SDS were solubilised in $1560 \mathrm{~mL}$ of ultrapure water and transferred into a $2000 \mathrm{~mL}$ four-necked jacketed reactor equipped with condenser and mechanical stirrer. Then, the solution, heated at $(343 \pm 1) \mathrm{K}$, was deoxygenated by purging with nitrogen for $1 \mathrm{~h}$. The addiction of $(1.0376 \pm 0.0001) \mathrm{g}$ of KPS, dissolved in $20 \mathrm{~mL}$ of deoxygenated water, allows the polymerization to begin and it is stopped after $5 \mathrm{~h}$. The resultant PNIPAM microgel was purified by dialysis against distilled water for two weeks, changing water frequently. Through gravimetric measurements, the final weight concentration $C_{w}$ of PNIPAM micro-particles was determined $\sim 1 \%$. In the second step of the two-step process for the synthesis of IPN microgels, $(140.08 \pm 0.01) \mathrm{g}$ of the recovered PNIPAM dispersion $\left(C_{w}=1.06 \%\right)$ was diluted with ultrapure water up to a volume of $1260 \mathrm{~mL}$ into a $2000 \mathrm{~mL}$ four-necked jacketed reactor, kept at $(295 \pm 1) \mathrm{K}$ by circulating water. Then, $5 \mathrm{~mL}$ of AAc monomer and (1.1080 \pm 0.0001$) \mathrm{g}$ of BIS crosslinker were added to the dispersion and the mixture was deoxygenated by bubbling nitrogen inside for $1 \mathrm{~h}$. $0.56 \mathrm{~mL}$ of accelerator TEMED were poured and the polymerisation was started with $(0.4447 \pm 0.0001) \mathrm{g}$ of initiator APS. The polymerisation reaction, carried out at $\mathrm{pH} 3$, was stopped by exposing to air and PAAc content, depending on the time at which the reaction is stopped. The resultant IPN was purified by dialysis against distilled water with frequent water changes for two weeks, and then lyophilised and redispersed in water to prepare samples at weight concentration $\mathrm{C}_{w}=1.0 \%$. The PAAc weight concentrations $\left(\mathrm{C}_{P A A C}\right)$ of the synthesized IPN samples were determined by combination of elemental and ${ }^{1} \mathrm{H}-\mathrm{NMR}$ analysis as described in reference [68], they were $\mathrm{C}_{P A A c}=2.7 \%, 4.5 \%, 15.4 \%$ and $24.6 \%$. Samples at low concentrations (lower than $\mathrm{C}_{w}=1.0 \%$ ) were obtained by dilution with distilled water from the same stock suspension at $\mathrm{C}_{w}=1.0 \%$ and adjusted at $\mathrm{pH}=5.5$. Moreover, samples at higher concentrations were obtained by evaporation from the sample $\mathrm{C}_{w}=1.0 \%$. Samples at fixed $\mathrm{C}_{w}$ and different $\mathrm{pH}$ were obtained by adding suitable quantities of $\mathrm{HCl}$ solution (in the range $0.1-1 \mathrm{M}$ ) for samples at acid $\mathrm{pH}$ or $\mathrm{NaOH}$ (in the range $0.1-10 \mathrm{M})$ for those at basic $\mathrm{pH}$.

\subsection{Differential Scanning Calorimetric Measurements}

In order to locate the volume phase transition typical of microgels, differential scanning calorimetric measurements were carried out with a Diamond Perkin-Elmer power compensation calorimeter equipped with the data acquisition software Pyris. Purge gas (nitrogen) was let through the DSC cell with a flow rate of $20 \mathrm{~mL} / \mathrm{min}$. Temperature was calibrated with indium zinc and distilled water and the indium latent heat of melting was used for calibrating heat flow. At constant pressure all heat supplied to the system $d Q / d t$ helps to increase its internal energy and is related to the specific heat of the system, therefore $[69,70]$ :

$$
\frac{d H}{d t}=\frac{d Q}{d t}=m c_{p} d T
$$

where $m$ is the mass of the sample, $c_{p}$ the specific heat and $d T$ the differential temperature variation. Thus, integrating, the area is [69]:

$$
\int_{T_{1}}^{T_{2}} \frac{d Q}{d t} d T=m r \int_{T_{1}}^{T_{2}} c_{p}(T) d T
$$

where $r=\frac{d T}{d t}$ is the heating/cooling rate. The thermodynamic quantity $d Q / d t$, i.e., the thermal power is measured with an instrument sensitivity of $0.2 \mathrm{~mW}$ Sealed standard aluminium sample pans with a volume of $10 \mu \mathrm{L}$ and $50 \mu \mathrm{L}$ were used as cells and references. Samples, initially at room temperature, were brought to $\mathrm{T}=278 \mathrm{~K}$ and held in this condition for $3 \mathrm{~min}$, then were heated to $\mathrm{T}=323 \mathrm{~K}$ across their volume phase transition at a rate of $10 \mathrm{~K} / \mathrm{min}$. An example of thermograms, i.e., the heat flow $d H / d t$ versus temperature $\mathrm{T}$, is displayed in Figure 2a for an IPN microgel at $C_{P A A c}=2.7 \%$ and $C_{w}=0.9 \%$. It represents the typical coil-to-globule transition associated to the thermosensitive PNIPAM microgel and it is reversible, as verified by cooling down the sample. 
All measurements were repeated several times in order to verify their reproducibility and to evaluate their uncertainty, all transitions were found to be reproducible and reversible. IPN microgels with four different PAAc contents, $C_{P A A c}=2.7 \%, 4.5 \%, 15.4 \%$ and $24.6 \%$, were investigated at different weight concentrations from $\mathrm{C}_{w}=0.3 \%$ to $10.0 \%$. The characteristic parameters of the different IPN microgels are reported in Table 2.

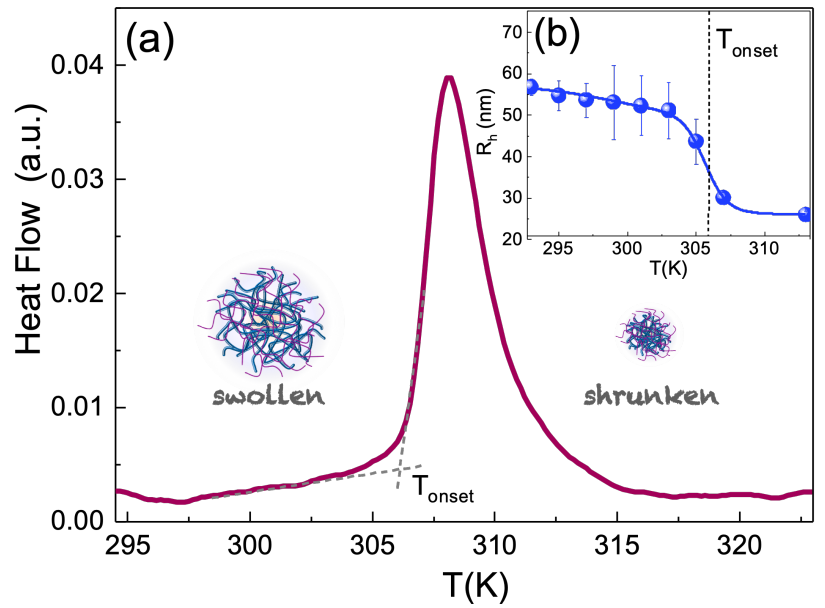

Figure 2. (a) DSC thermogram of an IPN microgel at $\mathrm{C}_{P A A c}=2.7 \%, \mathrm{C}_{w}=0.9 \%, \mathrm{pH} 5.5$ and heating rate $10 \mathrm{~K} / \mathrm{min}$. The onset temperature is indicated by the intersection of the dashed lines. (b) Hydrodynamic radius $R_{h}$, for the same IPN microgel, as a function of temperature measured in dilute conditions $\left(C_{w}=0.01 \%\right)$. The dashed line indicates the onset temperature obtained from DSC measurements.

Table 2. Characteristic parameters of IPN microgels at different PAAc contents at $\mathrm{pH} 5.5 . R_{h}$ is the particle hydrodynamic radius measured through DLS at T $=293 \mathrm{~K}$ and $\mathrm{T}=313 \mathrm{~K}$ at weight concentration $\mathrm{C}_{w}=0.01 \%, \alpha$ is the swelling ratio defined in the text through Equation (3), $\mathrm{C}_{P A A c}$, $\mathrm{C}_{\text {PNIPAM }}$ and $\mathrm{C}_{B I S}$ are respectively the contents of PAAc, PNIPAM and crosslinker BIS within particles measured through elemental and ${ }^{1} \mathrm{H}-\mathrm{NMR}$ analysis [68].

\begin{tabular}{cccccc}
\hline$C_{\boldsymbol{P A A c}}(\boldsymbol{\%})$ & $\boldsymbol{R}_{\boldsymbol{h}(\mathbf{2 9 3 K})}(\mathbf{n m})$ & $\boldsymbol{R}_{\boldsymbol{h}(\mathbf{3 1 3 K})}(\mathbf{n m})$ & $\boldsymbol{\alpha}$ & $\boldsymbol{C}_{\text {PNIPAM }}(\%)$ & $\boldsymbol{C}_{\boldsymbol{B I S}}(\%)$ \\
\hline 2.7 & $57 \pm 2$ & $26 \pm 1$ & 2.19 & 94.5 & 2.8 \\
4.5 & $66 \pm 2$ & $31 \pm 1$ & 2.13 & 91.5 & 4.0 \\
10.6 & $93 \pm 1$ & $52 \pm 1$ & 1.79 & 88.3 & 1.1 \\
15.4 & $120 \pm 1$ & $88 \pm 1$ & 1.36 & 79.2 & 5.4 \\
24.6 & $159 \pm 6$ & $130 \pm 3$ & 1.22 & 67.7 & 7.7 \\
\hline
\end{tabular}

\subsection{Dynamic Light Scattering Measurements}

The particle hydrodynamic radius $R_{h}$ of IPN microgels was measured through Dynamic Light Scattering (DLS) as a function of temperature T. An optical setup based on a solid state laser $(100 \mathrm{~mW})$ with monochromatic wavelength $\lambda=642 \mathrm{~nm}$ and polarised beam was used to probe IPN microgels suspensions in dilute regime. Measurements were performed at a scattering angle $\theta=90^{\circ}$ that corresponds to a scattering vector $Q=(4 \pi \mathrm{n} / \lambda)$ $\sin (\theta / 2)=0.018 \mathrm{~nm}^{-1}$. The hydrodynamic radii were obtained through the Stokes-Einstein relation: $R_{h}=\mathrm{k}_{B} \mathrm{~T} / 6 \pi \eta_{s} \mathrm{D}_{t}$ where $\mathrm{k}_{B}$ is the Boltzmann constant, $\eta_{s}$ the viscosity of the solvent, namely water, at the measured temperature and $\mathrm{D}_{t}$ the translational diffusion coefficient related to the relaxation time $\tau$ through the relation: $\tau=1 /\left(\mathrm{Q}^{2} \mathrm{D}_{t}\right)$. The relaxation time was obtained by fitting the autocorrelation function of scattered intensity through the Kohlrausch-William-Watts expression [71,72], $g_{2}(Q, t)=1+b\left[\exp \left(-(t / \tau)^{\beta}\right)\right]^{2}$, with the stretching exponent $\beta$ providing the deviation from the single exponential. Measurements were performed as a function of temperature at a heating rate $0.1 \mathrm{~K} / \mathrm{min}^{-1}$. The 
samples were held for $5 \mathrm{~min}$ at each temperature before measurement. An example of the hydrodynamic radius behaviour for a chosen IPN microgel is reported in Figure $2 b$.

To evaluate the capability of an IPN microgel particle to shrink, the swelling ratio [73] can be employed, it is defined as:

$$
\alpha=\frac{R_{h}^{\text {swollen }}}{R_{h}^{\text {shrunken }}}=\frac{R_{h(293 \mathrm{~K})}}{R_{h(313 \mathrm{~K})}}
$$

where $R_{h}^{\text {swollen }}$ and $R_{h}^{\text {shrunken }}$ are the hydrodynamic radii in the swollen and in the shrunken state. $R_{h}^{\text {swollen }}$ and $R_{h}^{\text {shrunken }}$ were chosen as the values at $\mathrm{T}=293 \mathrm{~K}$ and T=313 K, respectively. $\alpha$ values for the investigated IPN microgels are reported in Table 2: $\alpha$ decreases with increasing PAAc content, indicating a reduced capability of microgel to shrink as deeper discussed later.

\section{Results and Discussion}

In order to evaluate the thermal behaviour of IPN microgels across the volume phase transition as a function of weight concentration $\mathrm{C}_{w}$, PAAc content and $\mathrm{pH}$, we performed DSC measurements at four PAAc contents, different weight concentrations and seven different $\mathrm{pH}$, in the temperature range $(278-323) \mathrm{K}$, at heating rate $10 \mathrm{~K} / \mathrm{min}$.

Figure 2a shows, as an example, the thermogram of an IPN microgel with $\mathrm{C}_{P A A c}=2.7 \%$ and $\mathrm{C}_{w}=2.8 \%$ and $\mathrm{pH}$ 5.5. A peak of endothermic nature is observed in correspondence with the volume phase transition temperature, typical of the thermosensitive PNIPAM ( $\mathrm{T} \approx 305 \mathrm{~K}$ ), which indicates the transition from the swollen to the shrunken state of particles and indicates that, during heating, particles absorb energy to reach a new thermoreversible state characterized by a reduced size, changed mutual interactions and spatial configurations. The onset temperature, $\mathrm{T}_{\text {on }}$, indicated in Figure $2 \mathrm{a}$ as the intersection between two dashed lines, is in agreement with that found through DLS in Figure 2b, where the hydrodynamic radius $R_{h}$, measured in very dilute conditions $\left(\mathrm{C}_{w}=0.01 \%\right)$, shows the transition from a swollen to a shrunken state. At this concentration and PAAc content, the transition temperature of IPN microgels does not deviate remarkably from that of PNIPAM microgels [64].

\subsection{Effect of Heating Rate}

With the aim of understanding the effect of heating rate on the VPT temperature, Figure 3a shows the thermograms of IPN microgel with $\mathrm{C}_{P A A c}=2.7 \%$ and $\mathrm{C}_{w}=2.8 \%$ at different heating rates from 1 to $20 \mathrm{~K} / \mathrm{min}$. The heating rate greatly affects the volume phase transition temperature ranging from $305 \mathrm{~K}$ to $308 \mathrm{~K}$. This indicates that the heating rates are still high enough for the microgels to undergo a quasi-equilibrium phase transition and that the process of particle deswelling has extremely slow kinetics.

The onset temperatures are plotted as a function of the scan rate in Figure $3 \mathrm{~b}$ and by extrapolating the plot to zero scan rate, one obtains the adiabatic quasi-equilibrium phase transition temperature of $305.2 \mathrm{~K}$. Therefore, slower heating rates favour the occurrence of the transition at lower temperatures; on the other hand, by increasing heating rate, the transition temperature is shifted to higher values. This can be explained considering that, when temperature is gradually changed, microgel particles have enough time to reach the new final state, while with a rapid change of $\mathrm{T}$, they require more time to rearrange and the transition is shifted to higher temperatures. These results aid to reconcile different values for the VPT temperatures reported in several works, also in the case of the parental PNIPAM microgel where measurements were carried out with different techniques and heating rates. Figure $3 \mathrm{a}$ also indicates that the endothermic peaks, whose area below represents the energy required by the microgels to undergo the transition, are less pronounced at lower heating rates. In fact, at low heating rates, microgels have enough time to expel most of the solvent and less energy is required to achieve the necessary volume changes. On the contrary, at faster rates, the swelling kinetics are slower than the scan rate, the system is 
out of equilibrium and more heat is necessary for microgel deswelling. Normalized heat flow by the factor (temperature/mass) is plotted as a function of the scan rate in Figure 3c. By extrapolating the plot to zero scan rate, one obtains the quasi-equilibrium enthalpy variation normalized by the mass of $2.26 \mathrm{~J} / \mathrm{g}$.

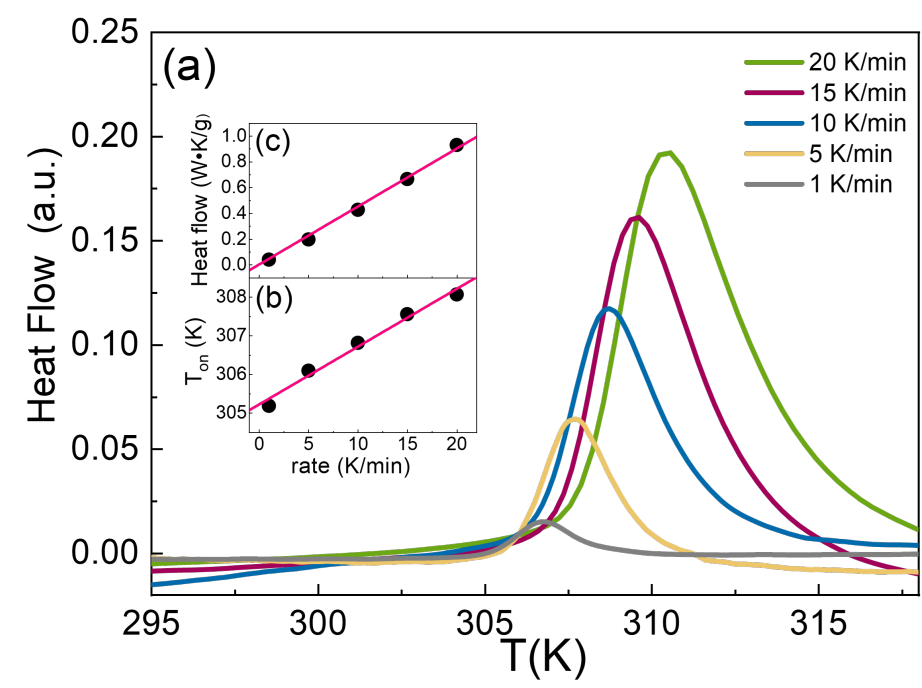

Figure 3. (a) DSC thermograms of IPN microgel at $\mathrm{C}_{P A A c}=2.7 \%, \mathrm{C}_{w}=2.8 \%$, $\mathrm{pH} 5.5$ and different heating rates. (b) Onset temperature and (c) Normalized heat flow as a function of heating rate. Lines are linear fits to data.

\subsection{Effect of Weight Concentration}

To understand how weight concentration affects the volume phase transition of IPN microgels we performed DSC measurements in the range $0.3 \%$ to $10.0 \%$. Figure $4 \mathrm{a}, \mathrm{b}$ show an example of thermograms for two IPN microgels, at low $\left(C_{P A A c}=2.7 \%\right)$ and high $\left(C_{P A A C}=24.6 \%\right)$ PAAc contents, at different weight concentrations and at fixed heating rate of $10 \mathrm{~K} / \mathrm{min}$. In both cases, with increasing weight concentration, the transition peak becomes higher and sharper since more particles require a greater amount of energy to undergo the VPT. Moreover, at the lowest PAAc content, the curves show the same plateau before and after the VPT, at variance with the highest concentration $C_{w}=10.0 \%$ where a step is observed.
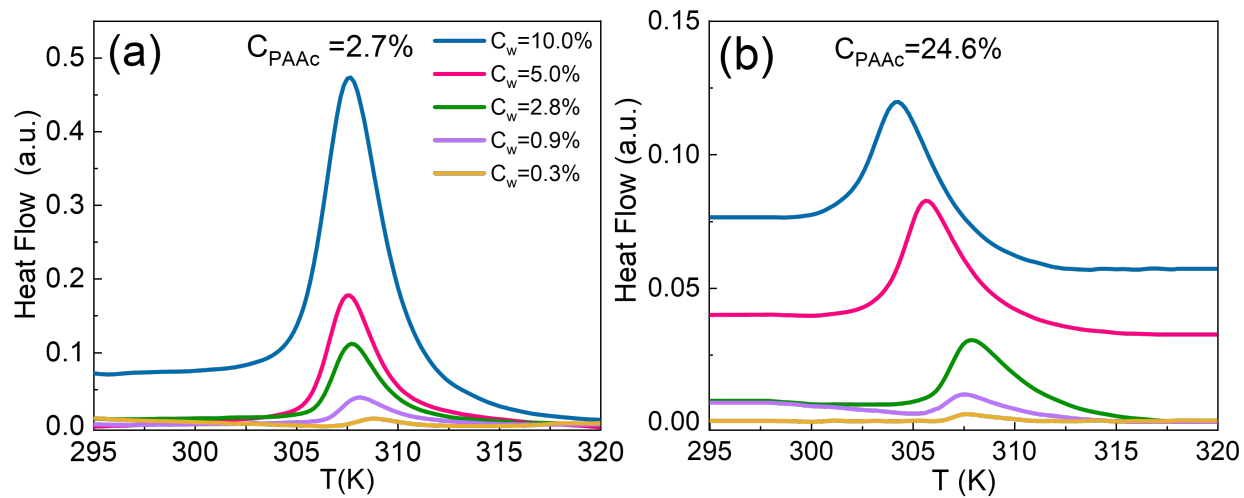

Figure 4. DSC thermograms for IPN microgels (a) at $\mathrm{C}_{P A A c}=2.7 \%$ and $(\mathbf{b}) \mathrm{C}_{P A A c}=24.6 \%$, pH 5.5, at different concentrations and fixed heating rate $10 \mathrm{~K} / \mathrm{min}$.

This latter behaviour is typical of a liquid-to-glass transition [74]. Instead, for IPN with $\mathrm{C}_{P A A C}=24.6 \%$, already at concentration $\mathrm{C}_{w}=0.9 \%$, the baseline variation appears, becoming even more evident at the highest concentrations (here thermograms are properly shifted upwards to better visualize the differences) suggesting the presence of a glass transi- 
tion that accompanies the typical VPT of microgels at a much lower $\mathrm{C}_{w}$ with respect to IPN with $\mathrm{C}_{P A A c}=2.7 \%$. These results provide a calorimetric interpretation of recent findings obtained through rheological measurements [75], DLS and X-ray photon correlation spectroscopy [76] carried out on the same sample where, by studying respectively the stress flow curves and the normalized intensity autocorrelation functions $g_{2}(q, t)-1$, we distinguished the transition from liquid to glassy state at a concentration around $C_{w}=(0.6-0.7) \%$. Overall, for the highest PAAc content, a further feature is observed: the transition temperature is shifted at lower values at higher concentrations as will be better discussed later.

\subsection{Effect of $p H$}

In order to evaluate the effect of $\mathrm{pH}$, we investigated the thermal behaviour of an IPN microgel with PAAc content $15.4 \%$ and $C_{w}=1.0 \%$ at $\mathrm{pH} 3.0,5.5,7.1,8.3,9.5,10.8,12.0$ and at heating rate $10 \mathrm{~K} / \mathrm{min}$, as shown in Figure $5 \mathrm{a}$. Thermograms are properly shifted upwards to better visualize the differences. As already reported in the introduction, the pH-sensitive PAAc network is characterized by a coil-to-globule transition around $\mathrm{pH} 5$ due to the ionization of the carboxylic group into $\mathrm{H}^{+}+\mathrm{RCOO}^{-}$. Below this $\mathrm{pH}$ it assumes a compact globular conformation while, by increasing $\mathrm{pH}$, the fraction of ionized groups $\mathrm{RCOO}^{-}$increases and PAAc expands into a coil conformation $[77,78]$. Therefore, tuning $\mathrm{pH}$ allows to tune water-particle and particle-particle interactions: at high $\mathrm{pH}$ in fact, the coil conformation of PAAc chains provides a more pronounced dangling chain structure to the IPN microgel particles. Moreover the $\mathrm{COOH}$ groups of PAAc are dissociated in $\mathrm{COO}^{-}$and $\mathrm{H}^{+}$preventing $\mathrm{H}$-bonding between different particles, but favouring like-charge attraction that results from counterion fluctuation due to the formation of temporary dipoles. This is evident from the growth of the structural relaxation time across the VPT for IPN microgel at $C_{P A A c}=19.2 \%$ and $C_{w}=0.9 \%$ which indicates a slowing down of the dynamics and the formation of aggregates [73]. Hence, at these $\mathrm{pH}$, interactions among particles and aggregation are favoured.
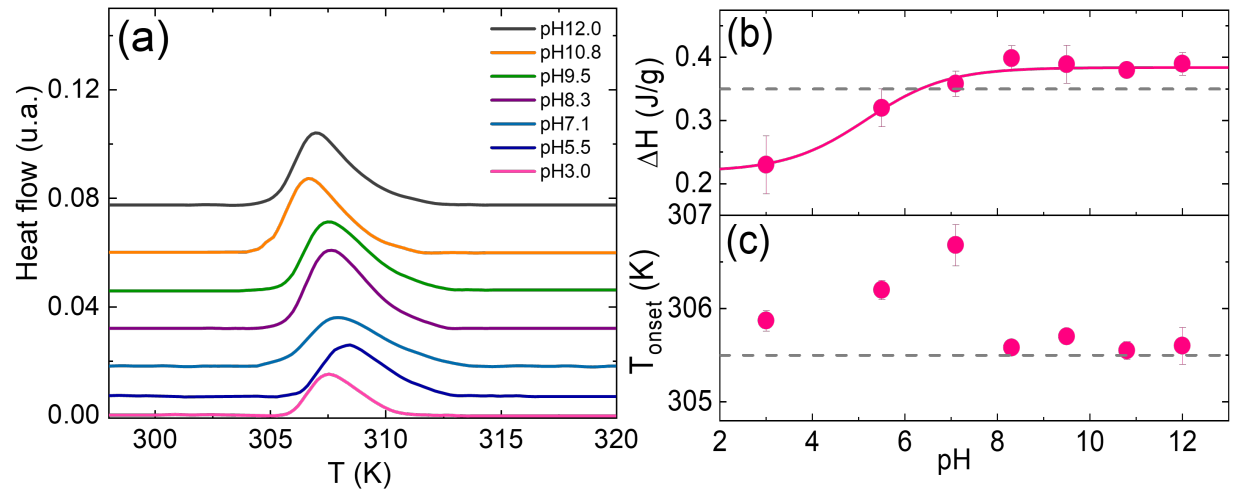

Figure 5. (a) DSC thermograms for an IPN microgels with $C_{P A A C}=15.4 \%, C_{w}=1.0 \%$ at different $\mathrm{pH}$ and at heating rate $10 \mathrm{~K} / \mathrm{min}$. (b) Area normalized by mass as a function of $\mathrm{pH}$ (pink line is a guide to eyes) and (c) Onset temperature. Dashed lines represent the values of pure PNIPAM.

On the contrary, at low $\mathrm{pH}$, PAAc is insoluble in water and hydrogen bonds between its carboxylic $(\mathrm{COOH})$ groups and the isopropyl $(\mathrm{CONH})$ groups of PNIPAM are formed (Figure 6a), with a consequent globule configuration that gives a more compact shape to the IPN particles and makes them more hydrophobic and with reduced capability of interaction both with water and other particles. This trend is reflected clearly in the behaviour of the area under the peak normalized by the sample mass, $\Delta \mathrm{H}(\mathrm{J} / \mathrm{g})$, (Figure $5 \mathrm{~b}$ ), and of the onset temperature, $\mathrm{T}_{\text {on }}$, (Figure $5 \mathrm{c}$ ). The area under the peak normalized by the sample mass, namely the normalized enthalpy variation, that is related to the dehydration process of the isopropylic groups of PNIPAM, increases with increasing $\mathrm{pH}$ and shows a change of slope around pH 5 (that reminds the typical PAAc titration curve), indicating that less energy is required to undergo the transition at low values. 
(a) low pH

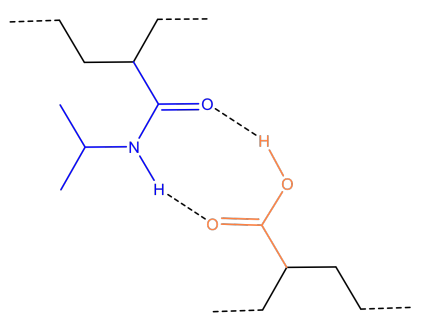

(b) high pH

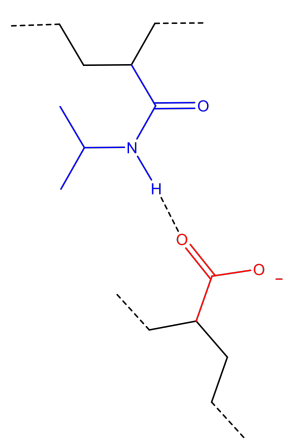

Figure 6. Sketch of the PNIPAM-PAAc interactions: (a) at low $\mathrm{pH}$, when the carboxylic groups $(\mathrm{COOH}$, in orange) of AAc are protonated, the formation of complexions with the amide groups (CONH, in blue) of NIPAM occurs, through two hydrogen bonds (dashed black lines); (b) at high $\mathrm{pH}$, the AAc carboxylic groups are deprotonated $\left(\mathrm{COO}^{-}\right.$, in red) and a single hydrogen bond may form with NIPAM.

In fact, at low $\mathrm{pH}$, most of the carboxylic groups $(\mathrm{COOH})$ of PAAc are protonated and a complexation with the amide groups $(\mathrm{CONH})$ of the NIPAM repeating units through hydrogen bonds occurs, as shown in Figure 6a. These repeating units involved in the complexation probably do not contribute to the transition, which then shows low values of enthalpy, due to the small amount of NIPAM units undergoing the process. However, increasing the $\mathrm{pH}$, the amount of deprotonated carboxylic acid increases and at high values the hydrogen bonds with NIPAM no longer happen, due to repulsive interactions (Figure 6b). Thus, the complexation is broken and almost all the NIPAM repeating units are involved in the transition, as shown by the value of $\Delta \mathrm{H}$ very similar to the one of pure PNIPAM (dashed line in the figure) $\Delta H=0.35 \mathrm{~J} / \mathrm{g}$. A similar behaviour is observed in Figure $5 \mathrm{c}$ for $\mathrm{T}_{\text {on }}$ that overlaps with the VPT temperature of PNIPAM $(305.5 \mathrm{~K})$ above $\mathrm{pH} 8$, confirming that PAAc no longer affect the PNIPAM transition thanks to the break up of the hydrogen bonds of the complexes between NIPAM and AAc. However, decreasing the $\mathrm{pH}$, an increase of $\mathrm{T}_{\text {on }}$ is observed around 7 , followed by a further slight decrease toward lower values, probably due to the complexation between NIPAM and AAc repeating units, which leads to an anticipation of the VPT. At these $\mathrm{pH}$, the completely open PAAc structure with PAAc dangling chains favours particle aggregation, resulting in an overall decrease of the transition temperature, as also found varying $\mathrm{C}_{w}$.

\subsection{Effect of PAAc Content}

With the aim of evaluating the effect of the second PAAc polymer network on thermal behaviour, we report in Figure 7a the heat flow of IPN microgels with different PAAc contents, $2.7 \%, 4.5 \%, 15.4 \%$ and $24.6 \%$, at $\mathrm{C}_{w}=10.0 \%$, $\mathrm{pH} 5.5$ and at heating rate $10 \mathrm{~K} / \mathrm{min}$. The area under the peak normalized by the sample mass decreases with increasing PAAc content, indicating that less energy is required to undergo the transition. This trend suggests that the endothermic transitions strongly depend on the presence of the second polymeric network of PAAc that hinders the contraction of the particles both because it constitutes a topological constraint [73] and also due to hydrogen bonds of PAAc with $\mathrm{H}_{2} \mathrm{O}$, since at $\mathrm{pH} 5.5$, above the critical $\mathrm{pH}$ threshold $\left(\mathrm{pK}_{a} \approx 4.5\right)$, polyacrylic acid becomes hydrophilic [64,79-81].

Furthermore, besides the steric hindrance of the PAAc chains, a nontrivial role is played by the crosslinker BIS, which, as shown in Table 2, is greater for the highest PAAc content. These findings agree with those of an interesting work by Grinberg and coworkers [64] where the volume phase transition of an interpenetrated microgel of PNIPAM and PAAc differs notably from both P(NIPAM-co-PAAc) and pure PNIPAM microgel showing a lower enthalpy, a larger transition width and an onset temperature shifted to higher values. They attribute this behaviour to the fact that interpenetration of the second network reduces 
the transition cooperativity. These results are also in agreement with a recent work [82] that compares the thermoresponsive behaviour of a double hydrogel network (DN) with that of a single hydogel network (SN). DN hydrogels display smaller enthalpy than SN, confirming that the presence of a second hydrophilic network (PAAc in our case) has a noticeable impact on thermal sensitivity. These arguments are also supported by the behaviour of the swelling ratio $\alpha$, defined through Equation (3) and shown in Figure $7 \mathrm{~b}$, that highlights a reduced shrinking capability for microgels with higher PAAc content.
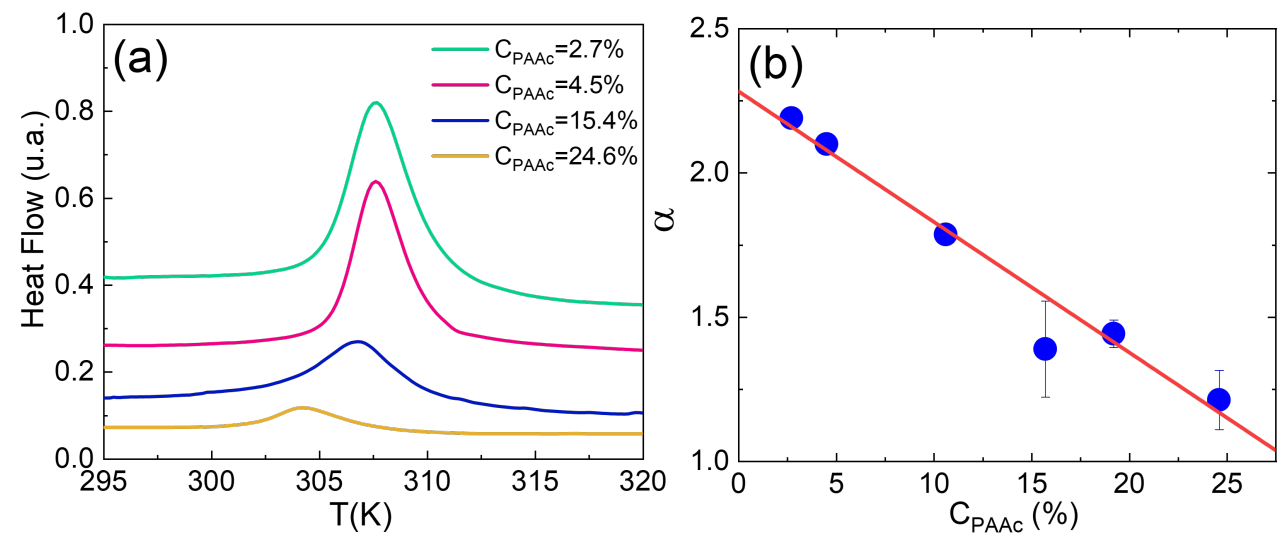

Figure 7. (a) DSC thermograms for IPN microgels with different PAAc contents at $C_{w}=10.0 \%, \mathrm{pH} 5.5$ and at heating rate of $10 \mathrm{~K} / \mathrm{min}$. (b) Swelling ratio from Equation (3) for IPN microgels at different PAAc contents.

In Figure 8a the onset temperatures are reported as a function of concentration at different PAAc contents: $\mathrm{C}_{P A A C}=2.7 \%, 4.5 \%, 15.4 \%$ and $24.6 \%$. For all the samples an almost constant behaviour is observed at low concentrations, followed by a decrease as concentration increases. In particular, for samples $C_{P A A c}=2.7 \%$ and $4.5 \%, \mathrm{~T}_{\text {onset }}$ slightly decreases in the investigated concentration range, while for microgels with higher PAAc contents it systematically bends at increasing concentrations with a deflection point that depends on PAAc content. These results can be interpreted considering that, at low PAAc content and weight concentration, $\mathrm{T}_{\text {onset }}$ corresponds to the typical LCST of PNIPAM while with increasing PAAc content and microgel concentrations the VPT is accompanied by the presence of a transition towards an arrested state, as highlighted in the description of Figure 4 . Such a transition is promoted for microgels at high $\mathrm{C}_{P A A C}$ indicating that, at high $\mathrm{C}_{w}$, PAAc contributes to a shift of the transition temperature at lower T. In fact, at this $\mathrm{pH}\left(\mathrm{pH}\right.$ 5.5), the ionization of the carboxylic group into $\mathrm{H}^{+}+\mathrm{RCOO}^{-}$occurs, the fraction of deprotonated moieties $\left(\mathrm{COO}^{-}\right)$is not negligible and the polymer expands towards a solvated open coil conformation $[79,83]$ where interparticle interactions and aggregation are favoured due to like-charge attraction [73]. This tendency is stronger at higher PAAc contents. Figure $8 \mathrm{~b}$ shows the enthalpy normalized by the sample mass $\mathrm{m}$ as a function of concentration. At fixed PAAc content, the area under the peak becomes greater with increasing weight concentration and this is explained considering that the system contains a large number of microgel particles, as anticipated qualitatively in Figure 3.

Moreover, a systematic decrease of energy is observed with increasing PAAc, confirming that microgels have a reduced deswelling capability when a second network is interpenetrated. An important feature emerges from Figure 8b: curves have a different shape by varying PAAc, for high PAAc contents, a rather linear increase at low concentrations is followed by a change in slope which generally occurs earlier in $\mathrm{C}_{w}$ with increasing $\mathrm{C}_{P A A c}$. Conceptually, the change of trend of enthalpy could be the hallmark of the existence of different phases in the system. 

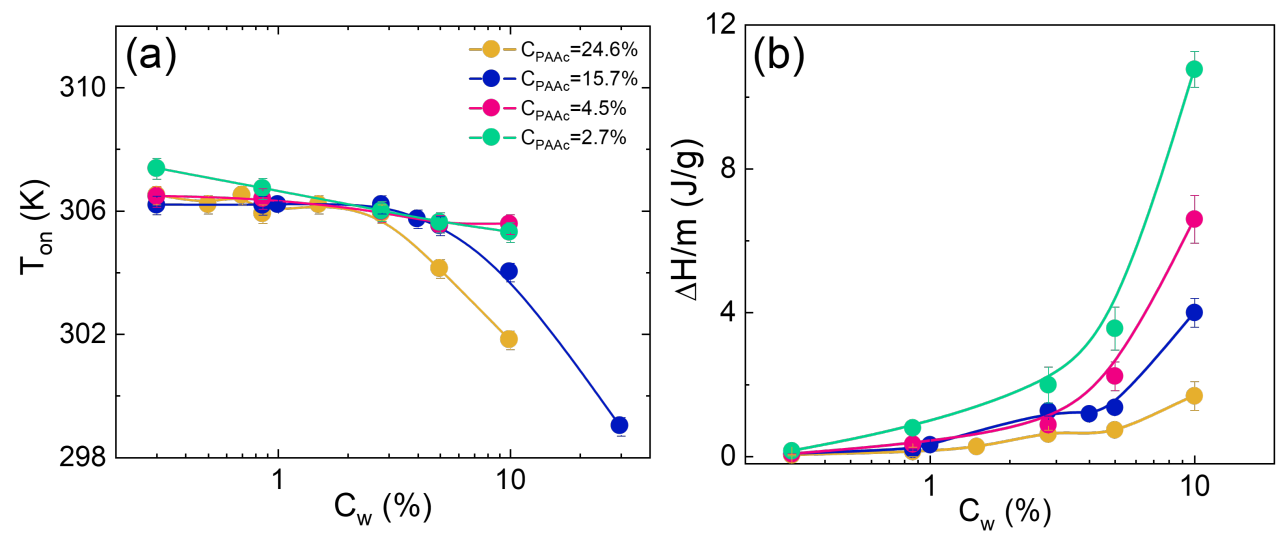

Figure 8. (a) $\mathrm{T}_{\text {onset }}$ and (b) $\Delta \mathrm{H} / \mathrm{m}$ versus $\mathrm{C}_{w}$ for IPN microgels with different PAAc contents at pH 5.5.

To better highlight phase changes, in Figure 9 the plot of $\Delta \mathrm{H} / \mathrm{m}$ versus $\mathrm{C}_{w}$ for the highest PAAc content $\mathrm{C}_{P A A c}=24.6 \%$ is shown. In particular, three different regions are distinguished: $\mathrm{C}_{w} \lesssim 0.7 \%, 0.7 \% \lesssim \mathrm{C}_{w} \lesssim 3.0 \%$ and $\mathrm{C}_{w} \gtrsim 3.0 \%$. A comparison with the apparent yield stress, obtained from rheological measurements discussed in reference [75], highlights the perfect agreement and provides a calorimetric characterization of three different kind of transition: between two viscous liquids at low microgel concentrations, a liquid-glass transition at intermediate concentrations and a transition between a glass and a jamming state at higher $\mathrm{C}_{w}$.

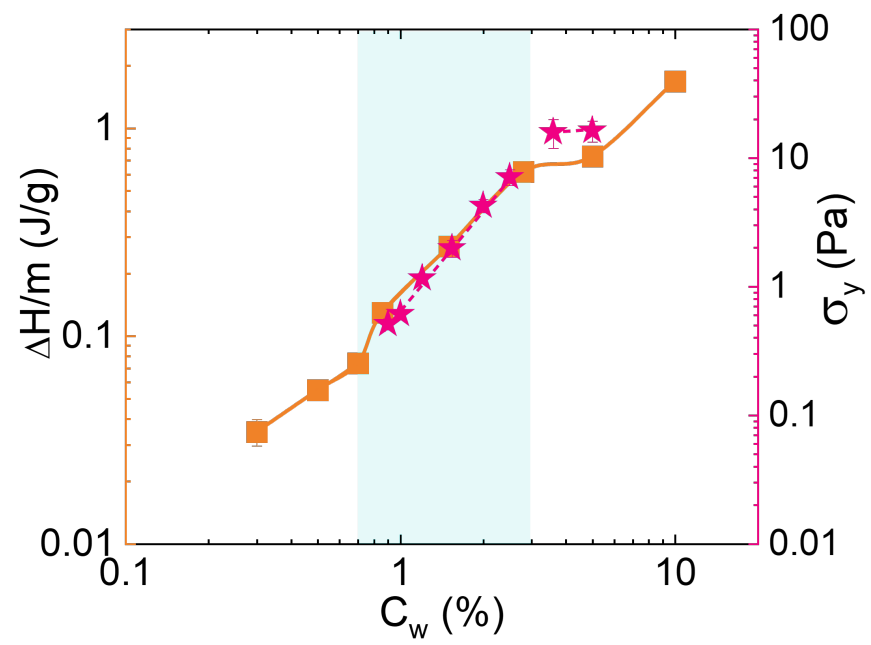

Figure 9. Comparison of $\Delta \mathrm{H} / \mathrm{m}$ versus concentration (orange squares, left axis) with the yield stress obtained from the rheological measurements (pink stars, right axis) reported in reference [75] for an IPN at $\mathrm{C}_{P A A C}=24.6 \%$ and $\mathrm{pH} 5.5$.

On the basis of the DSC analysis, we report in Figure 10 a preliminary temperatureconcentration phase diagram for an IPN microgel with $C_{P A A c}=24.6 \%$. Below the VPT, at low temperatures and concentrations, particles are free to diffuse and interactions are unfavoured so that microgel suspensions behave like viscous liquids: we call this phase "low temperature liquid (LTL)". With increasing concentration, the motion of the particles slows down and the system shows a glass state characterized by a caging regime in which particles rattle within the cage of their nearest neighbours. At the VPT, for low concentrations, the transition temperature overlaps to the LCST of PNIPAM while at increasing concentrations the VPT is accompanied by the formation of an arrested state giving rise to a downward deflection of the transition line. Above the VPT, when microgel particles collapse in the shrunken state, three different states are distinguished depending on concentration. (i) In the low concentration regime, the collapse of PNIPAM networks 
enhances PAAc exposure, however microgels suspensions are too diluted to form arrested states and still behave like a viscous liquid, we call it "high temperature liquid" (HTL). (ii) At increasing concentrations, the system exhibits a glassy state, here interactions among particles are favoured since the collapse of the thermosensitive PNIPAM promotes the exposure of PAAc and the like-charge attractions [73] resulting in the formation of an attractive glass [75]. (iii) Finally, when particles are packed at even greater concentrations, due their deformability, they interpenetrate each other, reaching a jammed state. These findings complement rheological measurements reported in ref. [75] and DLS and X-ray photon correlation spectroscopy in ref. [76], allowing to draw a $\mathrm{T}-\mathrm{C}_{w}$ phase diagram. The dividing lines between different states have been tentatively drawn as diagonal dashed lines considering that the transition concentration increases with decreasing temperature.

Finally, although the main phenomenology is preserved, the obtained results depends on PAAc content, in particular IPN microgels at lower PAAc reach glass or jammed states at higher concentrations, even outside the range investigated in this work.

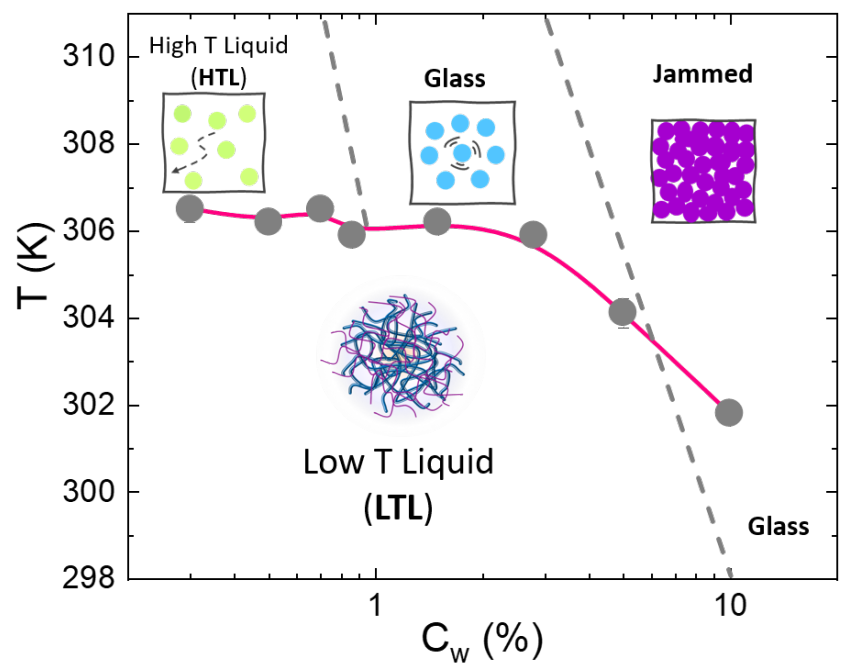

Figure 10. $\mathrm{T}-\mathrm{C}_{w}$ Phase diagram of IPN microgel suspensions with PAAc content $24.6 \%$ and $\mathrm{pH} 5.5$. The onset transition temperatures obtained with DSC measurements at a heating rate $\mathrm{r}=10 \mathrm{~K} / \mathrm{min}$ are plotted as a function of concentration.

\section{Conclusions}

In this work, we deeply investigated, through DSC, the thermal behaviour of microgels composed of interpenetrated polymer networks of poly( $N$-isopropylacrylamide) and poly(acrylic acid) at different heating rates, weight concentrations, $\mathrm{pH}$ and PAAc contents. The adiabatic quasi equilibrium phase transition temperature and enthalpy variation were obtained from heating rate investigation at different concentrations and PAAc contents. Two different scenarios appear: in dilute conditions and at low PAAc contents, the transition temperature, typical of PNIPAM microgels, is not significantly affected from interpenetration of PAAc network, while for high concentrations and PAAC, a marked decrease, attributed to the occurrence of a liquid-to-glass transition, is observed. Moreover, DSC analysis also revealed an increase of the overall calorimetric enthalpy with increasing concentration and a decrease with increasing PAAc content, respectively caused by emerging aggregation and by hindering of the contraction of particles due to the topological constraints of the second network and to complexation of PNIPAM. In fact, at the investigated $\mathrm{pH}$ 5.5, the PNIPAM contribution to enthalpy transition is reduced due to complexation of the PNIPAM amide groups with the carboxylic PAAc groups: the higher the PAAc content, the greater the inhibition of PNIPAM transition. This complexation is enhanced at low $\mathrm{pH}$ values and correspondingly, the enthalpy of transition decreases with decreasing $\mathrm{pH}$. Based on this DSC study, a temperature-concentration state diagram for IPN microgel composed of PNIPAM and PAAc was drawn for the first time. As expected 
from the complexity and tunability of the system, different states are present and this study opens the way for further investigations at increasing sample concentration. Moreover, the use of complementary techniques, such as small-angle X-ray scattering or small-angle neutron scattering, will permit to better elucidate the structure of the different states proposed in this paper. Therefore, the study clearly reveals that the interpenetration of PAAc into PNIPAM affects both the thermodynamics and the kinetics of the system. Furthermore, the correlation between the observed thermal behaviour and the rheological properties clearly indicates the possibility to trigger the arrest of the system by the temperature, once the composition of the IPN in terms of PAAc content and concentration of particles in the dispersion have been optimized ad hoc. Fine control of these microgels is fundamental also for their numerous technological applications in different fields such as drug delivery, tissue engineering, organ-on-chip devices, cultural heritage and microlens fabrication.

Author Contributions: Conceptualization, S.F., B.R. and R.A.; methodology, S.F., B.R. and R.A.; validation, S.F., B.R. and R.A.; formal analysis, S.F. and R.A.; investigation, S.F., E.B. and V.N.; resources, S.F., E.B. and M.B.; data curation, S.F. and R.A.; writing-original draft preparation, S.F. and R.A.; writing-review and editing, S.F., E.B., V.N., M.B., B.R. and R.A.; visualization, V.N., M.B. and B.R.; supervision, B.R. and R.A.; project administration, B.R. and R.A.; funding acquisition, B.R. and R.A. All authors have read and agreed to the published version of the manuscript.

Funding: We acknowledge financial support from Regione Lazio through POR FESR 2014-2020, Progetto Gruppo di Ricerca MICROARTE No. prot. A0375-2020-36515.

Institutional Review Board Statement: Not applicable.

Informed Consent Statement: Informed consent was obtained from all subjects involved in the study.

Data Availability Statement: The data presented in this study are available on request from the corresponding author.

Acknowledgments: This research was performed within the PhD program in "Mathematical Models for Engineering, Electromagnetics and Nanosciences" of Sapienza University of Rome.

Conflicts of Interest: The authors declare no conflict of interest.

\section{References}

1. Fernandez-Nieves, A.; Wyss, H.M.; Mattsson, J.; Weitz, D. Microgel Suspensions: Fundamental and Applications; Wiley-VCH: Weinheim, Germany, 2011.

2. Karg, M.; Pich, A.; Hellweg, T.; Hoare, T.; Lyon, L.A.; Crassous, J.; Suzuki, D.; Gumerov, R.A.; Schneider, S.; Potemkin, I.I.; et al. Nanogels and microgels: From model colloids to applications, recent developments, and future trends. Langmuir 2019, 35, 6231-6255. [CrossRef]

3. Wu, J.; Zhou, B.; Hu, Z. Phase Behavior of Thermally Responsive Microgel Colloids. Phys. Rev. Lett. 2013, 90, 31. [CrossRef] [PubMed]

4. Rubinstein, M.; Colby, R.H. Polymer Physics; Oxford University Press: Oxford, UK, 2003.

5. Fernandez-Nieves, A.; Puertas, A. Fluids, Colloids and Soft Materials: An Introduction to Soft Matter Physics; J. Wiley and Sons: Hoboken, NJ, USA, 2016.

6. Likos, C.N. Effective interactions in soft condensed matter physics. Phys. Rep. 2001, 348, 267-439. [CrossRef]

7. Pusey, P.N.; van Megen, W. Phase Behavior of Concentrated Suspensions of Nearly Hard Colloidal Spheres. Nature 1986, 320, 340-342. [CrossRef]

8. Berthier, L. Theoretical perspective on the glass transition and amorphous materials. Rev. Mod. Phys. 2011, 83, 587. [CrossRef]

9. Lu, P.J.; Zaccarelli, E.; Ciulla, F.; Schofield, A.B.; Sciortino, F.; Weitz, D.A. Gelation of particle with short range attraction. Nature 2008, 22, 499-503. [CrossRef]

10. Royall, C.P.; Williams, S.R.; Ohtsuka, T.; Tanaka, H. Direct observation of a local structural mechanism for dynamic arrest. Nat. Mater. 2008, 7, 556-561. [CrossRef]

11. Ruzicka, B.; Zaccarelli, E.; Zulian, L.; Angelini, R.; Sztucki, M.; Moussaïd, A.; Narayanan, T.; Sciortino, F. Observation of empty liquids and equilibrium gels in a colloidal clay. Nat. Mater. 2011, 10, 56-60. [CrossRef]

12. Angelini, R.; Zaccarelli, E.; de Melo Marques, F.A.; Sztucki, M.; Fluerasu, A.; Ruocco, G.; Ruzicka, B. Glass-glass transition during aging of a colloidal clay. Nat. Commun. 2014, 5, 4049. [CrossRef]

13. Pelton, R.H.; Chibante, P. Preparation of aqueous lattices with $N$-isopropylacrylamide. Colloids Surf. 1986, 20, 247-256. [CrossRef]

14. Wu, X.; Pelton, R.H.; Hamielec, A.E.; Woods, D.R.; McPhee, W. The kinetics of poly(N-isopropylacrylamide) microgel latex formation. Colloid Polym. Sci. 1994, 272, 467-477. [CrossRef] 
15. Zhang, Y.; Furyk, S.; Bergbreiter, D.E.; Cremer, P.S. Specific ion effects on the water solubility of macromolecules: PNIPAM and the Hofmeister series. J. Am. Chem. Soc. 2005, 127, 14505-14510. [CrossRef]

16. Sennato, S.; Chauveau, E.; Casciardi, S.; Bordi, F.; Truzzolillo, D. The double-faced electrostatic behavior of PNIPAm microgels. Polymers 2021, 13, 1153. [CrossRef]

17. Lyon, L.A.; Fernandez-Nieves, A. The Polymer/Colloid Duality of Microgel Suspensions. Annu. Rev. Phys. Chem. 2012, 63, 25-43. [CrossRef]

18. Annegarn, M.; Dirksen, M.; Hellweg, T. Importance of pH in Synthesis of pH-Responsive Cationic Nano-and Microgels. Polymers 2021, 13, 827. [CrossRef] [PubMed]

19. Vinogradov, S.V. Colloidal microgels in drug delivery applications. Curr. Pharm. Des. 2006, 12, 4703-4712. [CrossRef] [PubMed]

20. Smeets, N.M.B.; Hoare, T. Designing responsive microgels for drug delivery applications. J. Polym. Sci. Part A Polym. Chem. 2013, 51, 3027-3043. [CrossRef]

21. Fernández-Barbero, A.; Suárez, I.J.; Sierra-Martín, B.; Fernández-Nieves, A.; de Las Nieves, F.J.; Marquez, M.; Rubio-Retama, J.; López-Cabarcos, E. Gels and microgels for nanotechnological applications. Adv. Colloid Interface Sci. 2009, 147, 88-108. [CrossRef]

22. Dirksen, M.; Kinder, T.A.; Brändel, T.; Hellweg, T. Temperature Controlled Loading and Release of the Anti-Inflammatory Drug Cannabidiol by Smart Microgels. Molecules 2021, 26, 3181. [CrossRef] [PubMed]

23. Kabanov, A.; Vinogradov, S. Nanogels as Pharmaceutical Carriers: Finite Networks of Infinite Capabilities. Angew. Chem. Int. Ed. 2009, 48, 5418-5429. [CrossRef]

24. Saunders, B.R.; Laajam, N.; Daly, E.; Teow, S.; Hu, X.; Stepto, R. Microgels: From responsive polymer colloids to biomaterials. Adv. Colloid Interface Sci. 2009, 147-148, 251-262. [CrossRef]

25. Maya, S.; Sarmento, B.; Nair, A.; Rejinold, N.S.; Nair, S.V.; Jayakumar, R. Smart Stimuli Sensitive Nanogels in Cancer Drug Delivery and Imaging: A Review. Curr. Pharm. Des. 2013, 19, 7203-7218. [CrossRef] [PubMed]

26. Meena, L.K.; Rather, H.; Kedaria, D.; Vasita, R. Polymeric microgels for bone tissue engineering applications-A review. Int. J. Polym. Mater. Polym. Biomater. 2020, 69, 381-397. [CrossRef]

27. Newsom, J.P.; Payne, K.A.; Krebs, M.D. Microgels: Modular, Tunable Constructs for Tissue Regeneration. Acta Biomater. 2019, 88, 32-41. [CrossRef] [PubMed]

28. Yoshida, R.; Okano, T. Stimuli-Responsive Hydrogels and Their Application to Functional Materials; Springer: New York, NY, USA, 2010; pp. 19-43.

29. Rana, M.M.; la Hoz Siegler, H.D. Tuning the Properties of PNIPAm-Based Hydrogel Scaffolds for Cartilage Tissue Engineering. Polymers 2021, 13, 3154. [CrossRef]

30. Argentiere, S.; Siciliano, P.A.; Blasi, L. How Microgels Can Improve the Impact of Organ-on-Chip and Microfluidic Devices for 3D Culture: Compartmentalization, Single Cell Encapsulation and Control on Cell Fate. Polymers 2021, 13, 3216. [CrossRef] [PubMed]

31. Kim, J.; Nayak, S.; Lyon, L. Bioresponsive Hydrogel Microlenses. Am. Chem. Soc. 2005, 127, 9588-9592. [CrossRef] [PubMed]

32. Serpe, M.; Kim, J.; Lyon, L. Colloidal Hydrogel Microlenses. Adv. Mater. 2004, 16, 184-187. [CrossRef]

33. Nasimova, I.R.; Vyshivannaya, O.V.; Gallyamov, M.O.; Kozhunova, E.Y. Thermo- and pH-Sensitive Microgels Based on Interpenetrating Networks as Components for Creating Polymeric Materials. Polym. Sci. Ser. A 2019, 61, 773-779. [CrossRef]

34. Nasimova, I.R.; Doroganov, V.Y.R.A.P.; Kharitonova, E.P.; Kozhunova, E.Y. Microstructured Macromaterials Based on IPN Microgels. Polymers 2021, 13, 1078. [CrossRef]

35. Buratti, E.; Sanzari, I.; Dinelli, F.; Prodromakis, T.; Bertoldo, M. Formation and Stability of Smooth Thin Films with Soft Microgels Made of Poly ( $\mathrm{N}$-isopropylacrylamide) and Poly (acrylic acid). Polymers 2020, 12, 2638. [CrossRef]

36. Cai, T.; Wang, G.; Thompson, S.; Marquez, M.; Hu, Z. Derivative Colloidal Spheres as Building Blocks. Macromolecules 2008, 41, 9508-9512. [CrossRef]

37. Di Napoli, B.; Franco, S.; Severini, L.; Tumiati, M.; Buratti, E.; Titubante, M.; Nigro, V.; Gnan, N.; Micheli, L.; Ruzicka, B.; et al Gellan Gum Microgels as Effective Agents for a Rapid Cleaning of Paper. ACS Appl. Polym. Mater. 2020, 2, 2791-2801. [CrossRef] [PubMed]

38. Scotti, A.; Brugnoni, M.; Lopez, C.G.; Bochenek, S.; Crassous, J.J.; Richtering, W. Flow properties reveal the particle-to-polymer transition of ultra-low crosslinked microgels. Soft Matter 2020, 16, 668-678. [CrossRef]

39. Franco, S.; Buratti, E.; Ruzicka, B.; Nigro, V.; Zoratto, N.; Matricardi, P.; Zaccarelli, E.; Angelini, R. Volume fraction determination of microgel composed of interpenetrating polymer networks of PNIPAM and Polyacrylic acid. J. Phys. Condens. Matter 2021, 33, 174004. [CrossRef]

40. Yunker, P.J.; Chen, K.; Gratale, M.D.; Lohr, M.A.; Still, T.; Yodh, A.G. Physics in ordered and disordered colloidal matter composed of poly(N-isopropyl acrylamide) microgel particles. Rep. Prog. Phys. 2014, 77, 056601. [CrossRef] [PubMed]

41. Bae, Y.H.; Okano, T.; Kim, S.W. Temperature Dependence of Swelling of Crosslinked Poly(N,N'-alkyl substituted acrylamides) in Water. Polym. Phys. 1990, 98, 923-936. [CrossRef]

42. Pelton, R. Poly (N-isopropylacrylamide)(PNIPAM) is never hydrophobic. J. Colloid Interface Sci. 2010, 348, 673-674. [CrossRef] [PubMed]

43. Nigro, V.; Angelini, R.; Bertoldo, M.; Ruzicka, B. Swelling of responsive-microgels: Experiments versus models. Colloids Surf. A 2017, A532, 389-396. [CrossRef] 
44. Nigro, V.; Angelini, R.; Bertoldo, M.; Bruni, F.; Ricci, M.; Ruzicka, B. Local structure of temperature and pH-sensitive colloidal microgels. J. Chem. Phys. 2015, 143, 114904. [CrossRef]

45. Kodre, K.V.; Attarde, S.R.; Yendhe, P.R.; Patil, R.Y.; Barge, V.U. Differential Scanning Calorimetry: A Review. Res. Rev. J. Pharm. Anal. 2014, 3, 11-22.

46. Gill, P.; Moghadam, T.T.; Ranjbar, B. Differential Scanning Calorimetry Techniques: Applications in Biology and Nanoscience. J. Biomol. Tech. 2010, 21, 167-193. [PubMed]

47. Ferrari, C.; Tombari, E.; Salvetti, G.; Johari, G. Composition dependence and the nature of endothermic freezing and exothermic melting. J. Chem. Phys. 2007, 126, 124506. [CrossRef]

48. Sabín, J.; Prieto, G.; Sennato, S.; Ruso, J.M.; Angelini, R.; Bordi, F.; Sarmiento, F. Effect of Gd3+ on the colloidal stability of liposomes. Phys. Rev. E 2007, 74, 031913. [CrossRef]

49. Angelini, R.; Ruocco, G.; Panfilis, S.D.; Sette, F. Phase diagram of a solution undergoing inverse melting. Phys. Rev. E 2008, 78, 020502. [CrossRef] [PubMed]

50. Qu, L.J.; Li, B.; Wang, J.; Gu, Y.M. Application of DSC Technique in Study of Glass Ceramic. Adv. Mater. Res. 2010, 105-106, 743-745. [CrossRef]

51. Leyva-Porras, C.; Cruz-Alcantar, P.; Martínez-Guerra, V.E.S.E.; Piñón-Balderrama, C.I.; Martínez, I.C.; Saavedra-Leos, M.Z Application of Differential Scanning Calorimetry (DSC) and Modulated Differential Scanning Calorimetry (MDSC) in Food and Drug Industries. Polymers 2019, 12, 5. [CrossRef] [PubMed]

52. Slobozeanu, A.E.; Bejan, S.E.; Tudor, I.A.; Mocioiu, A.M.; Motoc, A.M.; Romero-Sanchez, M.D.; Botan, M.; Catalin, C.G.; Madalina C.L.; Piticescu, R.R.; et al. A review on differential scanning calorimetry as a tool for thermal assessment of nanostructured coatings. Manuf. Rev. 2021, 8, 1-15. [CrossRef]

53. Kawasaki, H.; Sasaki, S.; Maeda, H. Effects of the Gel Size on the Volume Phase Transition of Poly(N-isopropylacrylamide) Gels: A Calorimetric Study. Langmuir 1998, 14, 773-776. [CrossRef]

54. Grinberg, N.V.; Dubovik, A.S.; Grinberg, V.Y.; Kuznetsov, D.V.; Makhaeva, E.E.; Grosberg, A.Y.; Tanaka, T. Studies of the Thermal Volume Transition of Poly( $N$-isopropylacrylamide) Hydrogels by High-Sensitivity Differential Scanning Microcalorimetry. 1. Dynamic Effects. Macromolecules 1999, 32, 1471-1475. [CrossRef]

55. Aangenendt, F.J.; Mattsson, J.; Ellenbroek, W.G.; Wyss, H.M. Mechanics from Calorimetry: Probing the elasticity Elasticity for Responsive Hydrogels. Phys. Rev. Appl. 2018, 8, 014003. [CrossRef]

56. Woodward, N.C.; Chowdhry, B.Z.; Snowden, M.J.; Leharne, S.A.; Griffiths, P.C.; Winnington, A.L. Calorimetric Investigation of the Influence of Cross-Linker Concentration on the Volume Phase Transition of Poly( $N$-isopropylacrylamide) Colloidal Microgels. Langmuir 2003, 19, 3202-3211. [CrossRef]

57. Hoare, T.; Pelton, R. Calorimetric Analysis of Thermal Phase Transitions in Functionalized Microgels. J. Phys. Chem. 2007, 111, 1334-1342. [CrossRef]

58. Guo, Y.X.; Liu, Y.D.; Liu, R.; Tian, Y.; Chen, K.; Wang, L.M. Direct evidence of entropy driven fluid-like-glass-like transition in microgel suspensions. Appl. Phys. Lett. 2017, 110, 071902. [CrossRef]

59. Zanatta, M.; Orecchini, A.; Tavagnacco, L.; Buratti, E.; Chiessi, E.; Natali, F.; Bertoldo, M.; Zaccarelli, E. Atomic scale investigation of the volume phase transition in concentrated PNIPAM microgels. J. Chem. Phys. 2020, 152, 204904. [CrossRef]

60. Berndt, I.; Popescu, C.; Wortmann, F.J.; Richtering, W. Mechanics versus Thermodynamics: Swelling in Multiple-Temperature Sensitive Core-Shell Microgels. Angew. Chem. 2006, 45, 1081-1085. [CrossRef] [PubMed]

61. Buratti, E.; Tavagnacco, L.; Zanatta, M.; Chiessi, E.; Franco, S.; Ruzicka, B.; Angelini, R.; Orecchini, A.; Bertoldo, M.; Zaccarelli, E. The role of polymer structure on water confinement in poly( $N$-isopropylacrylamide) dispersions. J. Mol. Liq. 2021, unpublished work.

62. Snowden, M.J.; Chowdhry, B.Z.; Vincent, B.; Morris, G.E. Colloidal copolymer microgels of N-isopropylacrylamide and acrylic acid: $\mathrm{pH}$, ionic strength and temperature effects. J. Chem. Soc. Faraday Trans. 1996, 92, 24. [CrossRef]

63. Oropeza, M.V.C.; Souza, E.F.; Giudici, R. Study of the Porosity of the Microgel of pAA and Co-Polymer Microgel of p(AA-coNIPAM) Through the Thermoporometry Technique. Macromol. Symp. 2016, 367, 24-29. [CrossRef]

64. Grinberg, V.Y.; Burova, T.V.; Grinberg, N.V.; Buyanovskaya, A.G.; Khokhlov, A.R.; Kozhunova, E.Y.; Vyshivannaya, O.V.; Nasimova, I.R. Functionalized thermoresponsive microgels based on $N$-isopropylacrylamide: Energetics and mechanism of phase transitions. Eur. Polym. J. 2020, 133, 109722. [CrossRef]

65. Nigro, V.; Angelini, R.; Bertoldo, M.; Buratti, E.; Franco, S.; Ruzicka, B. Chemical-Physical Behaviour of Microgels Made of Interpenetrating Polymer Networks of PNIPAM and Poly(acrylic Acid). Polymers 2021, 13, 1353. [CrossRef]

66. Xia, X.; Hu, Z. Synthesis and Light Scattering Study of Microgels with Interpenetrating Polymer Networks. Langmuir 2004, 20, 2094-2098. [CrossRef]

67. Hu, Z.; Xia, X. Hydrogel nanoparticle dispersions with inverse thermoreversible gelation. Adv. Mater. 2004, 16, 305-309. [CrossRef]

68. Micali, N.; Bertoldo, M.; Buratti, E.; Nigro, V.; Angelini, R.; Villari, V. Interpenetrating Polymer Network Microgels in Water: Effect of Composition on the Structural Properties and Electrosteric Interactions. ChemPhysChem 2018, 19, 2894-2901. [CrossRef]

69. Höhne, G.; McNaughton, J.; Hemminger, W.; Flammersheim, H.J.; Flammersheim, H.J. Differential Scanning Calorimetry; Springer Science \& Business Media: Berlin/Heidelberg, Germany, 2003. 
70. Sarge, S.M.; Höhne, G.W.; Hemminger, W. Calorimetry: Fundamentals, Instrumentation and Applications; John Wiley \& Sons: Hoboken, NJ, USA, 2014.

71. Kohlrausch, R. Thermoresponsive poly-(N-isopropylmethacrylamide) microgels: Tailoring particle size by interfacial tension control. Pogg. Ann. Phys. Chem. 1854, 91, 179-214. [CrossRef]

72. Williams, G.; Watts, D.C. Non-symmetrical dielectric relaxation behavior arising from a simple empirical decay function. J. Chem. Soc. Faraday Trans. 1970, 66, 80-85. [CrossRef]

73. Nigro, V.; Angelini, R.; Rosi, B.; Bertoldo, M.; Buratti, E.; Casciardi, S.; Sennato, S.; Ruzicka, B. Study of network composition in interpenetrating polymer networks of poly( $\mathrm{N}$ isopropylacrylamide) microgels: The role of poly(acrylic acid). J. Colloid Interface Sci. 2019, 545, 210-219. [CrossRef]

74. Höhne, G.W.H.; Hemminger, W.F.; Flammersheim, H.J. Differential Scanning Calorimetry; Springer: New York, NY, USA, 2003.

75. Franco, S.; Buratti, E.; Nigro, V.; Zaccarelli, E.; Ruzicka, B.; Angelini, R. Glass and Jamming Rheology in Soft Particles Made of PNIPAM and Polyacrylic Acid. Int. J. Mol. Sci. 2021, 22, 4032. [CrossRef] [PubMed]

76. Nigro, V.; Ruzicka, B.; Ruta, B.; Zontone, F.; Bertoldo, M.; Buratti, E.; Angelini, R. Relaxation Dynamics, Softness, and Fragility of Microgels with Interpenetrated Polymer Networks. Macromolecules 2020, 53, 1596-1603. [CrossRef]

77. Stieger, M.; Richtering, W.; Pedersen, J.S.; Lindner, P. Small-angle neutron scattering study of structural changes in temperature sensitive microgel colloids. J. Chem. Phys. 2004, 120, 6197-6206. [CrossRef]

78. Romeo, G.; Ciamarra, M.P. Elasticity of compressed microgel suspensions. Soft Matter 2013, 9, 5401-5406. [CrossRef]

79. Swift, T.; Swanson, L.; Geoghegan, M.; Rimmer, S. The pH-responsive behaviour of poly(acrylic acid) in aqueous solution is dependent on molar mass. Soft Matter 2016, 12, 2542. [CrossRef] [PubMed]

80. Anghel, D.F.; Alderson, V.; Winnik, F.M.; Mizusaki, M.; Morishima, Y. Fluorescent dyes as model 'hydrophobic modifiers' of polyelectrolytes: A study of poly(acrylic acid)s labelled with pyrenyl and naphthyl groups. Polymer 1998, 39, 3035-3044. [CrossRef]

81. Arnold, R. The titration of polymeric acids. J. Colloid Sci. 1957, 12, 549-556. [CrossRef]

82. Hanykovà, L.; Krakovskỳ, I.; Šestàkovà, E.; Št'astnà, J.; Labuta, J. Poly(N,N'-Diethylacrylamide)-Based Thermoresponsive Hydrogels with Double Network Structure. Polymers 2020, 12, 2502. [CrossRef] [PubMed]

83. Katchalsky, A.; Eisenberg, H. Molecular weight of polyacrylic and polymethacrylic acid. J. Polym. Sci. 1951, 6, 145-154. [CrossRef] 